\title{
Beam Splitter Device
}

National Cancer Institute

\section{Source}

National Cancer Institute. Beam Splitter Device. NCI Thesaurus. Code C49841.

An optical device designed to take an electromagnetic beam and separate it into two or more parts. 